\title{
PERFORMANCE AND EMISSION CHARACTERISTICS OF CI ENGINE
}

\section{USING CERIUM OXIDE NANOPARTICLE WITH}

\section{WATER DIESEL EMULSION}

\author{
M. RUBAN ${ }^{1}$, M. GANDHI ${ }^{2} \&$ L. KARIKALAN ${ }^{3}$ \\ ${ }^{I}$ Assistant Professor, Department of Automobile Engineering, Vels Institute of science, Technology and \\ Advanced studies (VISTAS), Chennai, Tamil Nadu, India \\ ${ }^{2}$ PG Student, Department of Automobile Engineering, Vels Institute of science, Technology and \\ Advanced studies (VISTAS), Chennai, Tamil Nadu, India \\ ${ }^{3}$ Assosiate Professor, Department of Automobile Engineering, Vels Institute of science, Technology and
} Advanced studies (VISTAS), Chennai, Tamil Nadu, India

A detailed experimental study has been conducted to evaluate the effect of cerium oxide dose level in $15 \%$ water emulsion diesel. The emulsification method was used to produce E15. The span 80 and tween 80 were used as surfactants. The cerium oxide nano particle dose level in water emulsion diesel were 40, 60, 80 ppm respectively. The experiments were performed in a 4-cylinder, 4-stroke water cooled diesel engine at constant 1650 RPM, over different load condition. The properties such as viscosity, flash point, and calorific value were also determined as per standards. Experiments were conducted using diesel and different blends of the emulsion such as E15, E15CeO240, $\mathrm{E} 15 \mathrm{CeO260}$, and $\mathrm{E} 15 \mathrm{CeO} 280$ by varying the load on the engine. Performance and emission parameter of different blends of emulsion were compared to pure diesel. Results reported that cerium oxide blended fuels substantially improve the performance and reduce harmful pollutants.
\end{abstract}

KEYWORDS: Performance, Emission, CI Engine, Water Diesel Emulsion \& Cerium Oxide

Received: May 20, 2018; Accepted: Jun 10, 2018; Published: Jul 05, 2018; Paper Id.: IJMPERDAUG201828

\section{INTRODUCTION}

Diesel engine plays a significant role in power generation, transportation and industrial activities. The most benefits of the diesel over the fuel spark ignition engine embrace its sturdiness, reduced fuel consumption and lower emission of monoxide and unburned organic compound. Thanks to higher potency, a diesel engines square measure of high interest in light-weight duty vehicles. India stands 6th in the world of oil consuming countries with an oil utilization of 2,438,000 barrels per day and its pollution problem appeared many years ago.

Conventional fuels are found rather inadequate in rising emission characteristics that is that the terribly 1 st would like of preventative emission regulation. Nanofluids may decrease the emission parameter and might improve combustion potency by rising the ignition delay and fuel properties. Nanofluids had the potential because of the next- generation fuel for lowering emission and combustion potency improvement. Though Nano fluids have displayed tremendously exciting potential applications, some very important hinders additionally exist before commercialization of Nano fluids. 
Yang et al. [1], had evaluated an emulsion fuel with eighty two.4\% diesel, five-hitter water and12.6 Nano-organic additives by volume on a four cylinder, four stroke diesel motor. glycerine and polyethoxy-esters were used as the aerated additive. NP-9 is being the chemical agent to make the stable emulsion. The water driblet size was found to be ten0nm in emulsion oil with a typical diameter of $10 \mu \mathrm{m}$. in contrast to different emulsion fuel it absolutely was inexperienced in color and extremely stable. All the fuels were tested by variable the engine speed and cargo. The results were developed as compared to pure diesel it absolutely was ascertained that higher potency is achieved with emulsion oil and Nox emission was found to reduced. $\mathrm{HC}$ and $\mathrm{CO}$ emission square measure terribly low for each the tested fuels. it absolutely was found that ignition delay of emulsion fuel is slightly longer; but, the combustion length was shorter.

Scarpete et al.[2], had conducted the experiment on single cylinder direct injection diesel engine working between 1500-2700 rpm to evaluate the performance and emission characteristics of emulsified diesel fuel of 0,5,10,15 and 20 water/diesel ratios by volume. The Span 80 in the range of $1 \%$ was added to all emulsion blends and it was stirred using mixing machine at 1500-18000 rpm for several minutes. All the graphs were plotted against the speed. The results shown that the $20 \%$ water contents emulsion given highest brake specific fuel consumption among all blends but emulsion followed. It was seen that emulsion with $20 \%$ showed highest brake thermal efficiency. The emulsion with $20 \%$ water content had the lowest exhaust gas temperature. The emulsion with $20 \%$ water content found to lowest $\mathrm{CO}$ and $\mathrm{CO} 2$. It had been observed that the reduction of $\mathrm{HC}$ emission in the range of 60-93\% occurs due to the use of emulsion fuel. Emulsion fuel shown lessens smoke opacity. Much more water contents produced larger differences in NOx emissions among all the emulsions.

Rao et al. [3][14], evaluated the performance and emission characteristic of straight oil (SVO), small emulsions ESVO-80 (80\%, 15\%, and 05\% of oil, grain alcohol and butyl alcohol by volume) and ESVO-70 (70\%, 20\%, and 100\% of oil, grain alcohol and butyl alcohol by volume) compared with diesel on single cylinder, naturally aspirated, compression engine victimization pump set. Basic properties like body, hot worth, relative density were evaluated for all check fuels. it absolutely was detected that at full load, the brake thermal potency, with SVO, ESVO-80, ESVO-70 and diesel is concerning twenty- one.12\%, 23.33\%, 24.49\% and 31.85\% severally. The brake specific energy consumption of ESVOseventy was found to lower as compared to diesel. The neat oil rumored highest exhaust temperature $\left(402^{\circ} \mathrm{C}\right)$ as compared to diesel and emulsions. Carbon monoxide gas emission was lower with emulsions as compared to diesel. At full load, unburnt organic compound emissions were higher with oil and its emulsions as compared to diesel. Oxide and smoke opacity emission was seen to lower with oil and microemulsions as compared to diesel. In intensive amount, SVO exposed appliance choking, fuel pump harm; filter impeding however, emulsions of SVO with alcohol shown the lower body, improved volatility, higher combustion and fewer carbon deposits.

Sachuthananthan et al.[4][10][13][15], had played out the analyses on a normally suctioned water cooled 5H. P kirloskar single chamber consistent speed DI diesel motor to assess the execution and emanation attributes of steady $30 \%$ water-biodiesel emulsion(WBE) as fuel with 5\%, 10\% and 15\% mixes of diethyl ether(DEE). The static infusion timing was 23 BTDC and the fuel infusion weight was 200 bar. Every one of the outcomes was portrayed against the brake control. The outcomes show that the most extreme warmth discharge rate for $30 \% \mathrm{WBE}$ was observed to be $64.1 \mathrm{~J} / \mathrm{CA}$ degrees which emerged at 11 degrees BTDC and for $5 \%$ DEE it was $54.2 \mathrm{~J} / \mathrm{CA}$ degrees, for $10 \%$ DEE it was 58.1 J/CA degrees. It was discovered that the brake warm productivity at full load was expanded from $28.3 \%$ to $29 \%$ with $15 \%$ DEE expansion. The $\mathrm{HC}$ and $\mathrm{CO}$ levels were diminished from $75 \mathrm{ppm}$ to $40 \mathrm{ppm}$ and $0.175 \%$ vol. to $0.1 \%$ vol. separately at full 
load when contrasted with flawless Water-Biodiesel emulsions. The smoke mistiness was watched 4.2 BSU for diesel, 4.5 BSU for biodiesel and 2.5\%BSU for 30\% water-biodiesel emulsion. With the expansion of $15 \%$ DEE the smoke mistiness was altogether decreased and it was 1.6 BSU. The NOx level for DEE expansion is lower than that of water-biodiesel emulsion and slick diesel methods of activity. At full load, the NOx was found to 568ppm for $10 \%$ DEE expansion when contrasted with $651 \mathrm{ppm}$ with $30 \%$ water-biodiesel emulsion. Utilization of $15 \%$ DEE alongside the water biodiesel emulsion the $\mathrm{HC}$ discharges was followed just 65ppm at full load conditions which were the most reduced level among every one of the mixes. The excess $21.6 \%$ of oxygen by mass in DEE fundamentally decreased the CO. Test outcomes show that $15 \%$ DEE mix gives better execution and lower discharges contrasted with different mixes of emulsion fuel.

Ajin et al. [5][11] had led an examination to research the reactant action of cerium oxide, particularly in Nano estimated frame. Cerium oxide nanoparticles were set up by synthetic technique and added diesel to get a steady suspension. The execution tests were directed on a normally suctioned four stroke single chamber water-cooled pressure start the motor, working at evaluated speed 1500 RPM. Surfactant utilized was dodecenyl succinic anhydride which has HLB Value 1.34. Centralization of cerium oxide nanoparticle test in diesel was 5, 15, 25 and 35PPM. It was watched thickness, blaze and fire point increments with the expansion of nanoparticle. The heap tests were led by fluctuating the dosing level of cerium oxide nanoparticle in diesel, which demonstrates that hydrocarbon discharge was diminished on the expansion of synergist nanoparticle by around 40 to $45 \%$, particularly at higher load. The NOx outflow was observed to be diminished by a most extreme of $30 \%$, on the expansion of cerium oxide nanoparticle in diesel, particularly at higher load and further decrease up to half with the expansion of $5 \%$ volume division of surfactant treated nanoparticle.

Sajith et al. [6], assessed the impact of measurement level of cerium oxide nanoparticle in biodiesel. With a specific end goal to acquire the execution and emanation attributes, execution test was completed on a solitary chamber water-cooled coordinate infusion diesel motor, working at 1500 RPM. The extent of nanoparticle 10 to $20 \mathrm{~nm}$ and thickness of $7.13 \mathrm{~g} / \mathrm{mL}$ was utilized. The dosing level in base fuel was 20PPM, 40PPM and 80PPM individually. Every one of the outcomes was plotted against the heap on the test motor. Expanding pattern was seen in the properties of fuel like thickness and unpredictability with the expansion of nanoparticle. The outcomes demonstrated that a normal lessening of $25 \%$ to $40 \%$ in the hydrocarbon emanation was acquired for the added substance dosing level going from 40 to 80 PPM of the added substance. The NOx emanation was observed to be by and largely diminished on the expansion of cerium oxide nanoparticle to biodiesel. Where normal lessening of around 30\% was found to happen with dosing level of 80PPM nanoparticle. The diminishment impact of the fuel added substance on carbon monoxide discharge was not as conspicuous.

Shaisundaram et. al.[7] talked about the exploratory examination includes the investigation of engine execution and outflow qualities of a single cylinder diesel engine with yttria-and ceria-balanced out zirconia covering on a barrel liner and cylinder head. Shifted dosing levels were added to diesel in both uncoated and covered motors. The trial brought about observable changes in the chose warm obstruction covering and dosing of cerium oxide added substance nanoparticle in diesel. A surge of $2.1 \%$ in the brake warm productivity and downturn of $3 \%$ brake-particular fuel utilization when contrasted with standard diesel mode in the uncoated motor was observed. Discharge level of nitrogen oxide, carbon monoxide and hydrocarbon likewise experienced a significant decay.

Karthikeyan et al. [8][11], had evaluated the performance and emission characteristics of Promolin Stearin wax oil(B) biodiesel blended with 80\% diesel(D) and 50PPM and 100PPM concentration of Zinc Oxide(ZnO) on a single cylinder air-cooled and direct injection diesel engine operating at 1500 RPM. The average diameter of the zinc oxidenano 
particle was less than $100 \mathrm{~nm}$. The experiments were conducted for low, medium and heavy loads at rated speed with an injection pressure of 220 bar. All the results were plotted against the break mean effective pressure. The zinc oxide additive blends improved the calorific value but did not have any significant effect on the other properties. The BSFC was decreased and BTE was increased with the increase in the dosing level of $\mathrm{ZnO}$ in the fuel. The BSFC and BTE for B20, D80B20ZnO50 and D80B20ZnO100 were found to be $0.284,0.278,0.272$ in $\mathrm{kg} / \mathrm{kw}-\mathrm{hr}$ and $28 \%, 28.8 \%$, 29.96\% during experimentation. The $\mathrm{CO}$ and $\mathrm{HC}$ had appreciably reduced with the increase of the nano particle as compared to B20. The NOx emissions of all blended fuels did not have any considerable effect.

Lenin et al. [9], played out the trials on a solitary barrel air cooled Direct Injection diesel motor for assessment of diesel doped with metal added substances $\mathrm{MnO}(200 \mathrm{mg} / \mathrm{L})$ and $\mathrm{CuO}$ (200 mg/L). Sol- gel technique was utilized for nano fuel readiness. The scopes of nano molecule 50-210nm were affirmed with SEM. Every one of the outcomes have appeared against the heap. The adjustment in diesel fuel properties (consistency, streak point, and fire indicate) due presentation of nano metal oxide added substance was watched. The diesel fuel with nano metal oxide added substance had exhibited a minimal increment in execution. Brake warm productivity was expanded insignificantly by $4 \%$ from the traditional diesel fuel. For the DI Diesel motor, the hydrocarbon outflows were most astounding at bringing download. Accordingly, hydrocarbon outflows amid sitting condition have been a focal point of consideration. The diesel fuel with metal added substance was found to diminish from the regular diesel fuel activity amid the $25 \%$ load tests. At full load it was watched tentatively that $1 \%$ diminish in the hydrocarbon discharge, it was examined that manganese has the more grounded impact in decreasing the diesel fumes emanations. The fumes emanation estimations for the fuel with manganese added substance demonstrated that CO is lessened by $37 \%$, and NOX is diminished by $4 \%$.

\section{PRODUCTION OF WATER-DIESEL EMULSIONOIL}

The production of the water-diesel emulsion is done in two stages with the guide of the mechanical instigator. In an initial step, a blend ( $2 \%$ by vol.) of two non-ionic surfactants traverse 80 and tween 80 was set up by utilizing surfactant, with hydrophilic and lipophilic adjust esteem 8.

In the second step, the flawless diesel fuel ( $83 \%$ by vol.) is converged with surfactant blend and disturbed by methods for mechanical instigator for 15 minutes at a consistent speed of 2500 r. p. m. at the same time; the water(15\% by vol.) is included with the guide of the metering pump. The resultant item is the Water-diesel emulsion fuel (E15).

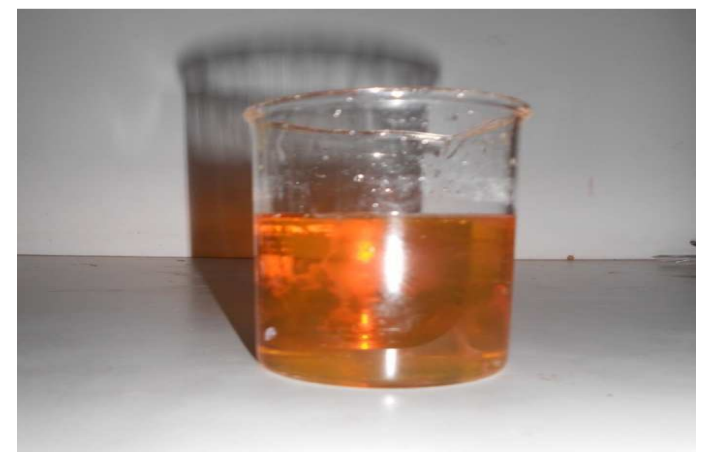

Figure 1: Surfactant Mixture used for Emulsion Fuel 


\section{PRODUCTION OF NANOPARTICLE BLENDED WATER-DIESEL EMULSION OIL}

Cerium oxide nanoparticle is chosen to investigate its effect on water-diesel emulsion oil is purchased from XINYU ADVANCED MATERIALS LIMITED, CHINA. In order to produce nanoparticle blended water-diesel emulsion oil, both ultrasonicator and mechanical agitator are used. Various steps used in the preparation of nanoparticle blended water-diesel emulsion oil are described below:

- Ultra sonication is used to disperse the cerium oxide nanoparticle (input 40 PPM) in the water for 90 minutes in the first step.

- Second, the surfactant mixture is produced in the same manner as it was adopted for E15 emulsion fuels.

- Thirdly, the mechanical instigator is utilized blend the slick diesel (83\% by vol.) and surfactant blend (2\% by vol.) at a consistent speed of 2500 r. p. m for 15 minutes. In the meantime, the (cerium oxide nanoparticle scattered in water) blend arranged prior is included by methods for the metering pump. The resultant item yields the cerium oxide nanoparticle mixed water-diesel emulsion fuel $\left(\mathrm{E} 15 \mathrm{CeO}_{2} 40\right)$

- The same procedure is adopted for dose level of 600PPM, 80PPM which yields $\mathrm{E} 15 \mathrm{CeO}_{2} 60$ and $\mathrm{E} 15 \mathrm{CeO}_{2}$ 80respectively.

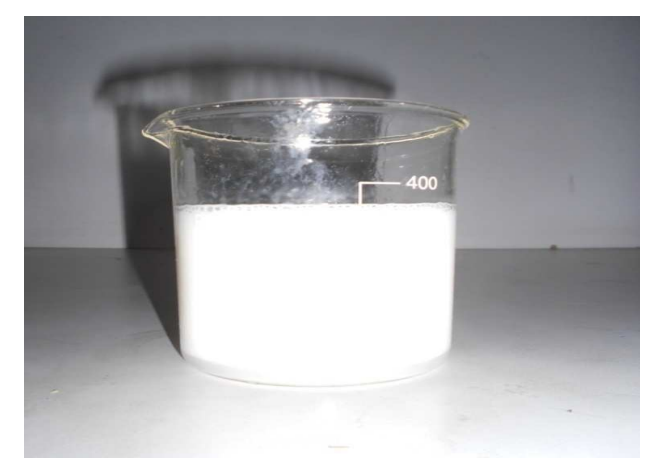

Figure 2: Nanoparticle Blended Emulsion Oil

\section{EXPERIMENTAL SET UP}

A Single cylinder, steady speed, Direct Injection engine was utilized to assess the engine performance and emission attributes of water diesel emulsion with cerium oxide. The diesel keeps running under various load conditions at a consistent speed of $1800 \mathrm{rpm}$ with the diverse plastic oil extents. The diesel motor was specifically connected with a swirl current dynamometer for changing the heaps from no heap $(0 \%)$ to full load $(100 \%)$. In light of the motor power, the motor load has fluctuated from no heap state of $0 \%, 25 \%$, half, $75 \%$ and the full load state of $100 \%$. The motor burdens are shifted physically with help of a vortex current dynamometer. Wind stream rate was estimated with an air drum fitted with an adjusted opening and the fuel stream was estimated utilizing volumetric (aligned burette) strategy. For fuel stream estimation, two fuel tanks were utilized; one is loaded with unadulterated diesel while esterified plastic oil is filled in another fuel tank. An AVL smoke meter was appended for estimating the smoke haziness and fumes gas temperatures. The test fix was introduced with AVL Indi smaller scale programming to get different readings and results amid activity. A five gas analyzer was utilized to gauge the emanation attributes, for example, $\mathrm{UHC}, \mathrm{CO}, \mathrm{NOx}, \mathrm{CO}_{2}$ and $\mathrm{O}_{2}$ esteem from the fumes gas. The execution and discharge tests were led at the pressure proportion of 17.5 and with evaluated control. 
The test was completed for various extents of water diesel emulsion mixed with the unadulterated diesel fuel. The execution examination of the motor at various appraised control was assessed as far as Brake Specific Fuel Consumption (BSFC), Brake Thermal Efficiency (BTE) and emission such as UHC, CO, CO2 and NO . The photographic view of the experimental set up used in this study.

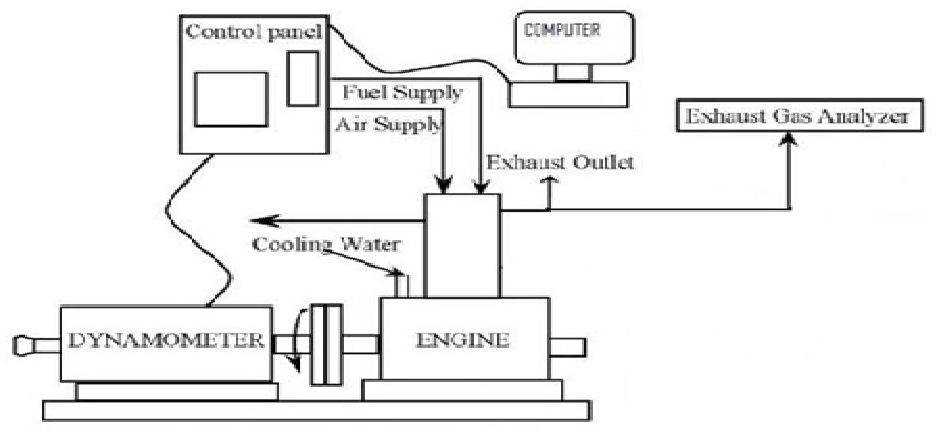

Figure 3: Experimental Setup Layout

Table 1: Specifications of the Test Engine

\begin{tabular}{|l|l|}
\hline \multirow{2}{*}{ Engine Type } & Single Cylinder, 4 Stroke, Water Cooled Engine \\
\cline { 2 - 2 } & Stoke $110 \mathrm{~mm}$, Bore $87.5 \mathrm{~mm}, 661 \mathrm{cc}$ \\
\hline Power & $3.50 \mathrm{~kW} @ 1500 \mathrm{rpm}$ \\
\hline Compression ratio & 16.5 \\
\hline Injection variation & $0-25$ degbTDC \\
\hline Dynamometer & Eddy current, Water cooled with Loading unit \\
\hline Fuel tank & 15 lit, Duel compartment with fuel metering \\
\hline
\end{tabular}

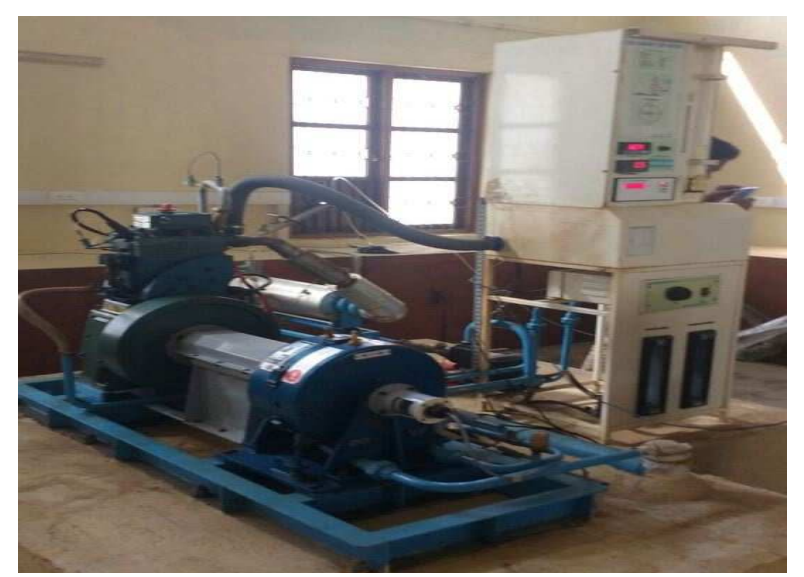

Figure 4: Experimental Set Up

\section{PERFORMANCE ANALYSIS}

\section{Fuel Consumption}

The test was performed for pure diesel fuel and then for different blends of emulsion E15, E15CeO240, $\mathrm{E} 15 \mathrm{CeO} 260, \mathrm{E} 15 \mathrm{CeO} 280$ sample and the load on engine was varied from $2.1 \mathrm{KW}$ to $13.2 \mathrm{KW}$. Experimentally, it was observed that the fuel consumption increases when the load was increased for all operations of diesel and emulsion blends as shown in figure 5. 


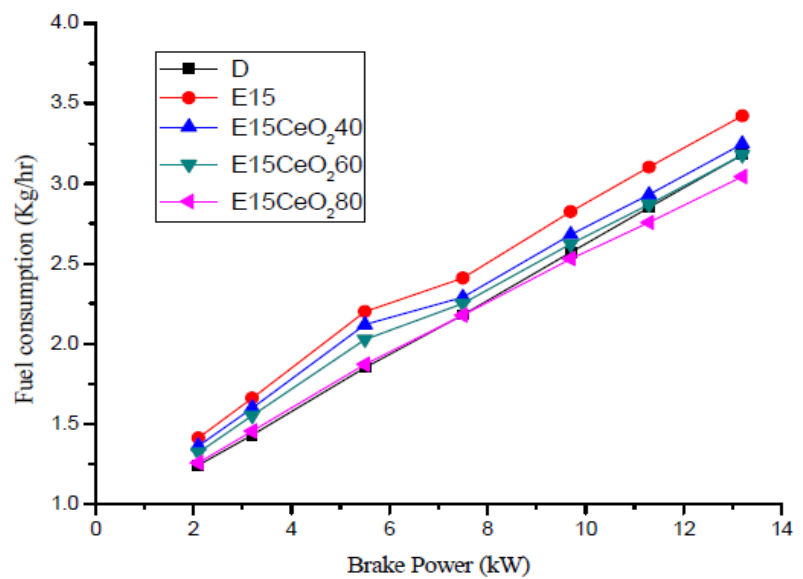

Figure 5: Variation of Fuel Consumption with Respect to Brake Power

It was likewise watched that fuel consumption diminishes when nanoparticle volume portion in the emulsion mix was expanded for any given load. Likewise, for E15 mix, the expansion in fuel utilization was more than that of different mixes and diesel activities at higher load conditions. This was because of the higher thickness and lower calorific estimation of B15 when contrasted with different mixes and customary Diesel fuel. At full load task most extreme energy of the motor was created that necessities higher measure of fuel vitality and because of lower vitality substance of E15 when contrasted with regular diesel and different mixes, fuel utilization increments for E5 when contrasted with diesel and alternate mixes at higher burdens. Nanoparticle mixed emulsion was observed to be enhanced with the expansion in their calorific incentive because of quality of cerium oxide nanoparticle which goes about as oxygen cradle, in this manner making the motor to devour less fuel contrasted with E15 to defeat indistinguishable load.

\section{Brake Thermal Efficiency}

The Brake warm proficiency is characterized as the proportion of work yield at the motor shaft to the vitality provided by fuel. It is a measure of the motor's capacity to make proficient utilization of fuel. The brake warm productivity for various mixes of fuel and that of regular diesel at various loads is accounted for in figure 6

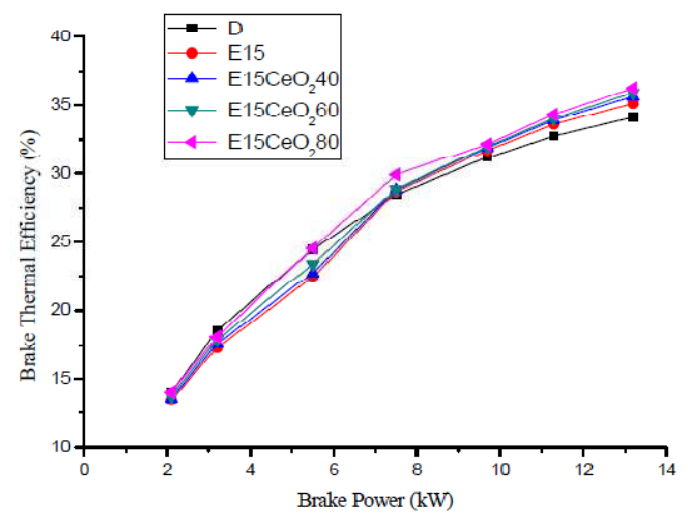

Figure 6: Variation of Brake Thermal Efficiency with Respect to Brake Power

The test was conducted for pure diesel fuel which is baseline fuel and then for different blends of emulsion oil $\mathrm{E} 15, \mathrm{E} 15 \mathrm{CeO}_{2} 40, \mathrm{E} 15 \mathrm{CeO}_{2} 60$, and $\mathrm{E} 15 \mathrm{CeO}_{2} 80$ samples and the load on the engine was varied from $2.1 \mathrm{KW}$ to $13.2 \mathrm{KW}$. 
It was observed that brake thermal efficiency increases when the load was increased for all operations of diesel and emulsion oil blend. On comparing all fuel blends, it was observed that the brake thermal efficiency of cerium oxide nanoparticle blended water in diesel emulsion fuel is higher among different fuel blends as the load increases. This is due to the cerium oxide nanoparticle encapsulation in water molecule which offers the secondary atomization immediate after the primary micro explosion phenomenon of the emulsion.

\section{EXHAUST EMISSION ANALYSIS}

\section{Unburned Hydrocarbon (HC)}

The variation of unburned hydrocarbon emission with respect to brake power for pure diesel fuel, which is baseline fuel and then for different blends of emulsion oil $\mathrm{E} 15, \mathrm{E} 15 \mathrm{CeO}_{2} 40, \mathrm{E} 15 \mathrm{CeO}_{2} 60$, and $\mathrm{E}^{2} \mathrm{CeO}_{2} 80$ samples is shown in figure 7. It was observed that E15 emulsion fuel produces a large magnitude of unburned hydrocarbon due to incomplete combustion. It was due to the presence of water and longer ignition delay of the fuel. Though, it was observed to be reduced in magnitude in case of cerium oxide nanoparticle blended water-diesel emulsion. It was due to the presence of cerium oxide nanoparticle which acts as oxygen buffer and promotes the complete combustion. Moreover, cerium oxide gets converted to a cerous oxide $\left(\mathrm{Ce}_{2} \mathrm{O}_{3}\right)$ by supplying enough oxygen for reduction of hydrocarbon as well as for soot.

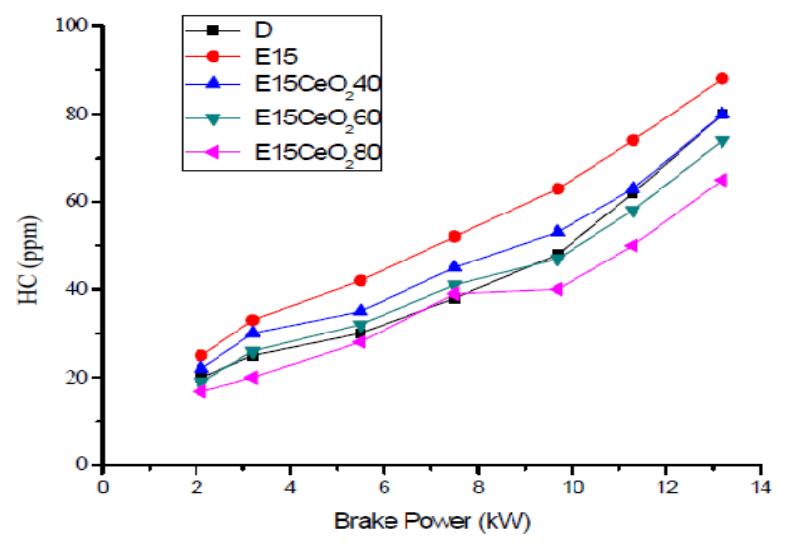

Figure 7: Variation of Unburned Hydrocarbon with Respect to Brake Power

\section{Carbon Monoxide (CO)}

Carbon monoxide highly relies upon the air-to-fuel proportions comparative to the stoichiometric ratio. In most cases, $\mathrm{CI}$ engine function with the lean mixture and thus results in lower $\mathrm{CO}$ emission. The variation of $\mathrm{CO}$ emission with respect to brake power is shown in figure 8. It was observed that $\mathrm{CO}$ emission in case of cerium oxide nanoparticle blended emulsion oil was marginally improved due to the secondary atomization produced by emulsion fuel, reduces the air requirement for emulsion blend due to presence of nanoparticle causes rapid evaporation which results in rapid mixing of water molecule inside diesel droplets thus reducing the air requirement which in turn results in less conversion of unburned carbon molecule to carbon monoxide. However, the magnitude of CO emission was high for E15 due to longer ignition delay and lower calorific value. The $\mathrm{CO}$ emission was observed to decrease at all loads respective of dose level of cerium oxide nanoparticle, but at high load catalytic activity was not that prominent. 


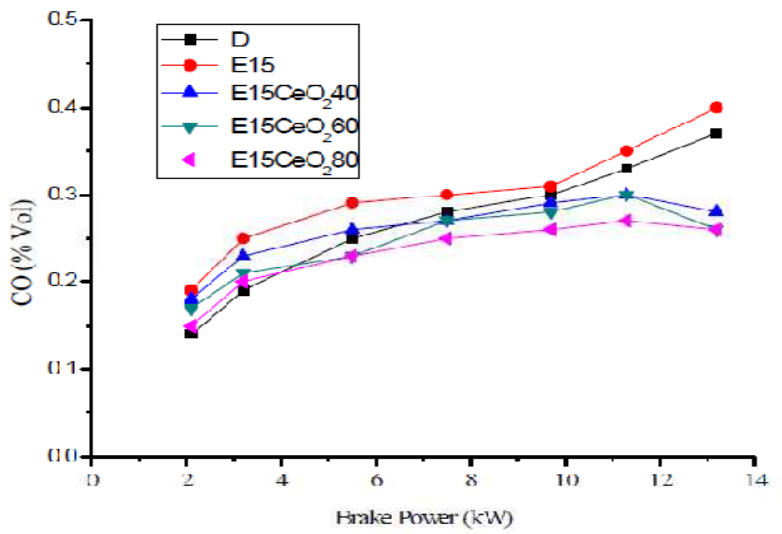

Figure 8: Variation of Carbon Monoxide with Respect to Brake Power

\section{Nitrogen Oxide (NOx)}

The response of NOx emission with respect to brake load for various fuel blends is depicted in figure 9 . It was observed that there is a fair reduction in NOx emission magnitude of E15 emulsion oil. This was due to water present in emulsion oil takes heat which is present inside the cylinder to evaporate which in turn results in lowering of flame temperature. There was a further reduction in NOx emission magnitude was found to occur in case nanoparticle blended emulsion fuel.

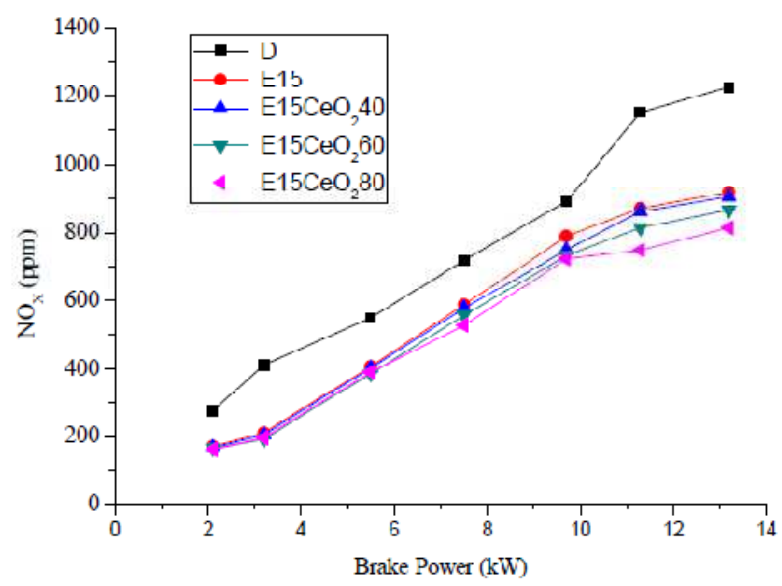

Figure 9: Variation of Nitrogen Oxide with Respect to Brake Power

\section{Smoke Opacity}

The Smoke opacity for various mixes of fuel and that of ordinary diesel at various load is accounted for in figure 10. The test was led for unadulterated diesel fuel which was gauge fuel and afterward, for various mixes of $\mathrm{E} 15, \mathrm{E} 15 \mathrm{CeO}{ }_{2}$ 40, $\mathrm{E} 15 \mathrm{CeO}_{2} 60$, and $\mathrm{E} 15 \mathrm{CeO}_{2} 80$ tests and the heap on the motor was changed from $2.1 \mathrm{KW}$ to $13.2 \mathrm{KW}$. It was watched that smoke mistiness increments for all mixes as the heap expanded. Diesel fuel demonstrates the higher greatness of smoke obscurity over the whole load extend. In any case, the smoke darkness in the event of E15 was found to lessen because of miniaturized scale blast of emulsion fuel enhancing the vanishing of fuel which brings about a change in blending with air. 


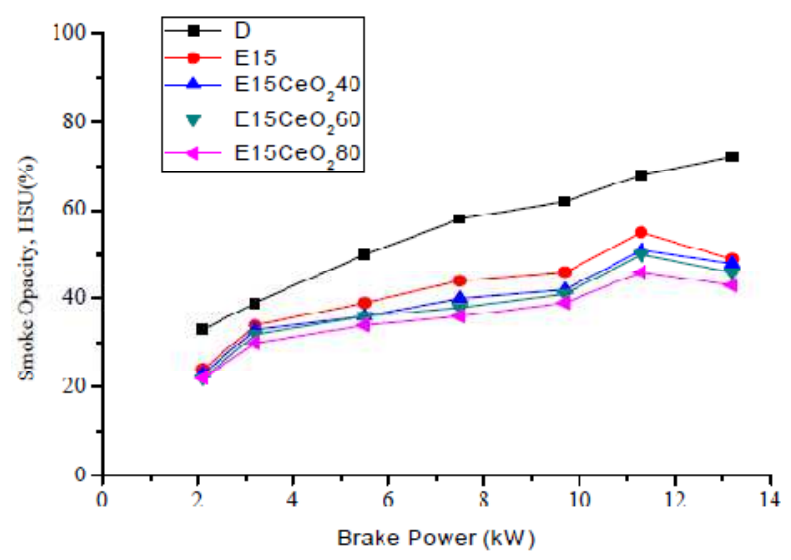

Figure 10: Variation of Smoke Opacity with Respect to Brake Load

\section{CONCLUSIONS}

On comparing all fuel blends, it was observed that the brake thermal efficiency of cerium oxide nanoparticle blended water in diesel emulsion fuel is higher among different fuel blends as the load increases. It was observed that E15 emulsion fuel produces the large magnitude of unburned hydrocarbon due to incomplete combustion. It was due to the presence of water and longer ignition delay of the fuel. The $\mathrm{CO}$ emission was observed to decrease at all loads respective of dose level of cerium oxide nanoparticle, but at high load catalytic activity was not that prominent. There was a further reduction in NOx emission magnitude was found to occur in case nanoparticle blended emulsion fuel. Diesel fuel demonstrates the higher greatness of smoke obscurity over the whole load extend. In any case, the smoke darkness in the event of E15 was found to lessen because of miniaturized scale blast of emulsion fuel enhancing the vanishing of fuel which brings about a change in blending with air.

\section{REFERENCES}

1. Yang, W. M., An, H., Chou, S. K., Chua, K. J., Mohan, B., Sivasankaralingam, V., Raman, V., Maghbouli, A. and Li, J., 2013. Impact of emulsion fuel with nano-organic additives on the performance of diesel engine. Applied energy, 112, pp.1206-1212.

2. Karikalan, L. and Chandrasekaran, M., 2015. Karanja Oil Biodiesel: A Potential Substitution For Diesel Fuel In Diesel Engine Without Alteration. ARPN Journal of Engineering and Applied Sciences, 10(1).

3. Scarpete, D., 2013. Diesel-Water Emulsion, An Alternative Fuel To Reduce Diesel Engine Emissions. A Review. Machines, Technologies, Materials, 7, pp.13-16.

4. Rao, N., Premkumar, B. S. and Yohan, M., 2012. Performance and emission characteristics of straight vegetable oil-ethanol emulsion in a compression ignition engine. ARPN Journal of Engineering and Applied Sciences, 7(4), pp.447-52.

5. Sachuthananthan, B. and Jeyachandran, K., 2007. Combustion, performance and emission characteristics of water-biodiesel emulsion as fuel with DEE as ignition improver in a DI diesel engine. Journal of Environmental Researh and Development Vol, 2(2).

6. Karikalan, L. and Chandrasekaran, M., 2015. Effect of varying fuel injection pressure of Selective Vegetable oil biodiesel on CI engine performance and pollutants. International Journal of ChemTech Research, 8(12), pp.312-318.

7. Sajeevan, A. C. and Sajith, V., 2013. Diesel engine emission reduction using catalytic nanoparticles: an experimental investigation. Journal of Engineering, 2013. 


\section{Water Diesel Emulsion}

8. Sajith, V., Sobhan, C. B. and Peterson, G. P., 2010. Experimental investigations on the effects of cerium oxide nanoparticle fuel additives on biodiesel. Advances in Mechanical Engineering, 2, p.581407.

9. Loganathan, K. and Chandrasekaran, M., 2013. Investigation on emission characteristics of CI Engine using vegetable oil with SCR technique. International Journal of Renewable Energy Research (IJRER), 3(4), pp.969-975.

10. Shaisundaram, V. S., Chandrasekaran, M., Mohan Raj, S. and Muraliraja, R., 2018. Investigation on the Effect of Thermal Barrier Coating at different Dosing Levels of Additives of cerium oxide Nanoparticle Fuel on Diesel in CI Engine. International Journal of Ambient Energy, (just-accepted), pp.1-19.

11. Karthikeyan, S., Elango, A. and Prathima, A., 2014. Performance and emission study on zinc oxide nano particles addition with pomolion stearin wax biodiesel of CI engine.

12. Lenin, M. A., Swaminathan, M. R. and Kumaresan, G., 2013. Performance and emission characteristics of a DI diesel engine with a nanofuel additive. Fuel, 109, pp.362-365.

13. Senthilkumar, P., and G. Sankaranarayanan. "Production of waste polyethylene bags in to oil and studies performance, emission and combustion characteristics in di diesel engine." International journal of humanities, arts, medicine and science 3 (2015): 149-158.

14. Karikalan, L., Chandrasekaran, M. and Sudhagar, K., 2013. Comparative studies on vegetable oil usage in CI engines as an alternative to diesel fuel. IREME Journal, 7(4), pp.705-715.

15. Sivaganesan, S., Chandrasekaran, M. and Ruban, M., The Influence of Bio Additive on the Various Compression Ratio with Diesel and Mahua Methyl Ester Biodiesel in DI Diesel Engine.

16. Sivaganesan, S., Chandrasekaran, M. and Ruban, M., 2017, March. Impact of Various Compression Ratio on the Compression Ignition Engine with Diesel and Jatropha Biodiesel. In IOP Conference Series: Materials Science and Engineering Vol. 183, No. 1, p. 012039.

17. Kumar, Pravin, and A. Rehman. "Performance and Emission Characteristics of Dual Injection in Compression Ignition (CI) Engine."

18. S. Sivaganesan, C. Dhanasekaran, M. Chandrasekaran \& A. Parthiban, 2018, Feb. The Impact Of Various Compression Ratio And Influence Of Bio Additive With Jatropha Methyl Ester Biodiesel In Di Diesel Engine. In International Journal of Mechanical and Production Engineering Research and Development (IJMPERD), Vol. 8, Issue 1, P-989-996.

19. S. Sivaganesan and M. Chandrasekaran, 2015, December. The Influence Of Thermal Barrier Coating On The Combustion And Exhaust Emission In Turpentine Oil Powered Di Diesel Engine. In ARPN Journal of Engineering and Applied Sciences. Vol. 10, Issue 22.

20. S. Sivaganesan and M. Chandrasekaran, 2016. Performance and Emission Analysis of Compression Ignition Engine with Methyl Ester of Jatropha and Diesel. In Indian journal of science and technology, vol.9, Issue 26. 
